\title{
Prevalence of Aedes Mosquitoes during the First Outbreak of Zika in Jaipur City, India
}

\author{
Raj Kumar Singh', Sukhvir Singh \\ ${ }^{1}$ ICMR-National Institute of Malaria Research, Sector-8, Dwarka, New Delhi, India. \\ ${ }^{2}$ National Vector Borne Disease Control Programme, 22 Sham Nath Marg, New Delhi, India. \\ DOI: https://doi.org/10.24321/0019.5138.201924
}

I $\mathbf{N} \quad \mathbf{F} \mathbf{O}$

\section{Corresponding Author:}

Sukhvir Singh, National Vector Borne Disease Control Programme, 22 Sham Nath Marg, New Delhi, India.

E-mail Id:

sukhvir_nicd@yahoo.co.in

Orcid Id:

https://orcid.org/0000-0001-8756-7867

How to cite this article:

Singh RK, Singh S. Prevalence of Aedes Mosquitoes during the First Outbreak of Zika in Jaipur City, India. J Commun Dis 2019; 51(3): 33-39.

Date of Submission: 2019-06-26

Date of Acceptance: 2019-09-18

\section{$\begin{array}{llllllll}\mathbf{A} & \mathbf{B} & \mathbf{S} & \mathbf{T} & \mathbf{R} & \mathbf{A} & \mathbf{C} & \mathbf{T}\end{array}$}

The entomological investigations were made in residential, commercial and public places in various localities of Jaipur city during outbreak of Zika in October 2018 with a view to assist, support, supervise and advise the State Health Authorities for mosquito control activities in Zika reported area in the city. During the study, 2035 houses were randomly checked to detect Aedes mosquito breeding, out of which Aedes mosquito breeding could be found in 651 houses in residential area. Out of 7104 domestic containers, 1054 were positive for Aedes mosquito breeding in all kinds of water holding containers indoors or outdoors and House Index ( $\mathrm{HI})$, Container Index $(\mathrm{Cl})$ and Breteau Index (BI) were $37.45,21.86$ and 57,59 respectively. All commercial areas and public places were found positive with Aedes mosquito breeding and over all $\mathrm{Cl}$ was 39.98. Aedes aegypti was the predominant species in various localities like residential, commercial and public places in Jaipur, while Aedes albopictus breeding were also detected in outdoor breeding habitats in the garden and parks. The highest positivity of Aedes breeding was recorded in houses or outdoor in cemented tank left in open spaces (2.11), followed by Mud pots for drinking of birds (1.39), domestic desert coolers (1.23), fountains (1.16), flower pots (0.84), Junk materials (0.75) and discarded tyres (0.59). Ae. aegypti breeding was detected in all the localities, where Zika cases were recorded. Ae. aegypti population was most prevalent in all the entire localities irrespective to the number of Zika cases.

Keywords: Zika Virus Fever, Aedes Breeding, Jaipur, Zika Virus out Break

\section{Introduction}

Zika Virus Infection (ZIKVI) is a newly re-emerge mosquito borne viral disease almost common arboviral disease is caused by flavivirus (family-Flaviviridae) and spread by the infected female Aedes mosquitoes. ${ }^{1}$ It was first identified in rhesus monkeys in 1947 and in 1952 in humans from Uganda forest and later in United Republic of Tanzania. ${ }^{1}$ In 1968, Zika virus was first isolated in Nigeria from human blood samples and many outbreaks of ZIKVI have been reported from the different countries as Asia, America, and Africa, in the Pacific in the year 2007. The South Pacific has been first experienced of Zika and its first outbreak in Yap Island in the Federated States of Micronesia. In 2013, French Polynesia of Brazil has been recorded first outbreak of Zika from the northeast part of the country and to contain outbreak of Zika successfully, but confirmed 
the disease of Zika Virus (ZIKV) in October 2015. After that many other countries and territories of the Americas have been reported the disease of ZIKV. $^{2}$

Since 2007, the disease of ZIKVI has been documented in 46 countries including 34 territories which reported this infection and World Health Organization (WHO) has regular monitor the epidemiologically and risk assessment. ${ }^{1}$ In India, first time four confirmed cases of ZIKVI were reported in 2017, out of which three cases in Bapunagar area of Ahmedabad, Gujarat and one case in Krishnagiri district of Tamil Nadu. Recently fifth case of ZIKVI was reported on 21 September 2018, from Shastri Nagar area of Jaipur city (capital of Rajasthan), India ${ }^{3}$ and first ZIKVI occurred in an elderly lady during regular monitoring in September 2018 and Govt. of India and State Health Authorities (SHAs) of Jaipur, Rajasthan confirmed the disease of ZIKVI as an outbreak in October $2018 .^{3}$ A total of 157 confirmed cases of ZIKVI without any death were reported and few unreported cases as of $2^{\text {nd }}$ November 2018 by the National Vector Borne Disease Control Programme (NVBDCP) has been identified including 63 pregnant woman; all the cases have been laboratory-confirmed by Reverse Transcriptase Polymerase Chain Reaction (RT-PCR). Subsequent few cases of ZIKV were also reported from Bhopal, Siroh and Sagar districts of Madhya Pradesh and Siwan district of Bihar state by the NVBDCP ${ }^{4}$ during September to November 2018. Recently ZIKV has also been detected in Ae. aegypti from Jaipur, confirmed by National Institute of Virology (NIV), Pune it's as a vector of Zika Virus Disease (ZIKVD). ${ }^{4}$ Aedes mosquitoes are the vector of three mosquito borne viral disease namely Dengue, Chikungunya and Zika, in many cities including rural areas and almost all over India; presently the vector of these diseases is spreading in the areas because of increasing unplanned urbanization with their population, unreliable water supply and water storage practices or manmade problems. ${ }^{5}$ For the prevention of vector borne disease, the vector surveillance is more essential tool to evaluate entomological data required for vector control strategies. ${ }^{6}$

There is no vaccine available for prevention of Zika Virus Infection Disease (ZIKVID) and only one DNA vaccine is being under trials. Therefore, the best method for prevention of ZIKVID is protection against day biter Aedes mosquitoes and controlling of mosquitoes is only one way to stop the transmission of Vector Borne Disease (VBD). Controlling of mosquitoes can be achieved by enhanced Integrated Vector Management (IVM) method. ${ }^{7}$ The central team deputed to Jaipur from the Emergency Medical Relief (EMR) Division of the Directorate General of Health Services (DGHS), Govt. of India (GOI) to contain the ZIKVD spread and to supervise, assist, support and advise the SHAs for mosquito control activities and to identify high risk areas of ZIKVI in the city. During this work, the central team also carried out entomological study to cross-check Aedes mosquitoes in various Zika affected municipal wards of Jaipur in October 2018 and results of the study are presented in this communication.

\section{Material and Methods}

\section{Location \& Geography of Study Area}

Geographical area of Jaipur district of the Rajasthan state is $11143 \mathrm{~km}^{2}$ and it is located on the eastern border of the Thar Desert. The city is located at a height of 1417 feet above sea level and it is popularly known as Pink city. The city is surrounded by the Aravalli hills from three sides which safeguard it from the desert and forests. The district has a total population of 6626178 (as of census 2011). The average rainfall is $650 \mathrm{~mm}$, temperature ranging minimum $5^{\circ} \mathrm{C}$ and maximum $45^{\circ} \mathrm{C} .^{8}$

\section{Entomological Investigations}

The entomological study was carried out in 65 localities of urban areas of Jaipur city including rural area of the district Jaipur with the officers and their field staff from National Centre for Disease Control (NCDC), Delhi, Regional Office of Health \& Family Welfare (ROHFW), GOI, Jaipur and SHAs Jaipur. Daily field investigations and vector control activities included discussions with senior officers of the state health authorities were reviewed and central team also made field visits for understanding the vector prevalence and control measures during October 2018.

All localities were selected on the basis of confirmed daily Zika cases reported by the SHAs, Jaipur during the outbreak. The residential, commercial premises and public places were randomly selected to cross check to find out the Aedes breeding in all the wet containers present in and around the premises (Table 1). A total of 20 houses or more depend on situation of outbreak in each locality. Localities were visited and larval collections were made simultaneously in each locality following the single larval technique. ${ }^{5,9,10}$ The central team also checked the public places including commercial areas, like Gardens, Parks, Bus Stand, Railway Station, Railway Hospital, Fort, Mosque, Temple and Gurdwara (Sikh temple). All types of breeding habitats in Zika reported area like cemented tanks, overhead tanks, drums, junk materials, desert cooler, discarded tyres etc. were screened properly for the presence of larval stage in all kinds of containers indoors or outdoors and with the help of flash light and pipette, having enamel tray white background for the better visibility, while bigger containers were searched with the help of the dipper of $250 \mathrm{~mL}$ capacity. The type of breeding habitats and their location were recorded properly and data were analyzed and calculated in terms of different indices like Container Index $(\mathrm{Cl})$, House Index $(\mathrm{HI})$, Breteau Index (B1) as per WHO procedure. ${ }^{6}$ Adult stage of Aedes mosquitoes identified up to species level with the help of standard identification keys. ${ }^{11}$ 
Table I.Aedes larval indices in Zika affected areas in Jaipur city

\begin{tabular}{|c|c|c|c|c|c|c|c|}
\hline Localities searched & Houses & Houses & Containers & Containers & HI & $\mathrm{Cl}$ & BI \\
\hline Residential area & visited & positive & searched & positive & (\%) & (\%) & (\%) \\
\hline JDA Bapu. Nagar, Kachchi Basti & 100 & 24 & 337 & 47 & 24 & 13.94 & 47 \\
\hline Ram Nagar, Shastri Nagar & 48 & 26 & 123 & 43 & 54.16 & 34.95 & 89.58 \\
\hline Vijay Nagar, Bhatta Basti & 23 & 13 & 68 & 35 & 56.52 & 51.47 & 152.12 \\
\hline Sanjay Nagar, Bhatta Basti & 10 & 8 & 26 & 10 & 80 & 38.46 & 100 \\
\hline Bhatta Basti, Shastri Nagar & 20 & 11 & 45 & 15 & 55 & 33 & 75 \\
\hline Tata Nagar, Shastri Nagar & 46 & 25 & 184 & 36 & 54.34 & 19.56 & 78.26 \\
\hline Shivaji Nagar, Shastri Nagar & 91 & 35 & 248 & 62 & 38.46 & 25 & 68.13 \\
\hline Shivaji Nagar, Nahari ka Naka & 50 & 16 & 80 & 19 & 32 & 23.7 & 38 \\
\hline DP Colony, Nahari ka Naka & 25 & 11 & 117 & 21 & 44 & 17.9 & 84 \\
\hline Subhash Nagar, Shastri Nagar & 16 & 7 & 90 & 15 & 43.7 & 16.6 & 93.7 \\
\hline New Jalupura, Shastri Nagar & 33 & 01 & 39 & 01 & 3.03 & 2.56 & 3.03 \\
\hline Shiv Shakti Nagar & 20 & 14 & 37 & 17 & 70 & 45.9 & 85 \\
\hline Subhash Colony, Shastri Nagar & 20 & 11 & 27 & 13 & 55 & 48.1 & 65 \\
\hline Housing Board Colony & 19 & 6 & 22 & 7 & 31.5 & 31.8 & 36.8 \\
\hline Azad Colony, Nahari ka Naka & 20 & 17 & 31 & 22 & 85 & 70.9 & 110 \\
\hline Phozi Nagar, Kachchi Basti, Amba Bari & 64 & 22 & 206 & 27 & 34.3 & 13.1 & 42.1 \\
\hline Kailash Nagar & 20 & 10 & 35 & 19 & 50 & 54 & 95 \\
\hline James Colony & 20 & 7 & 40 & 14 & 35 & 35 & 70 \\
\hline RPA Colony & 99 & 17 & 324 & 19 & 17.1 & 5.8 & 19.9 \\
\hline JP Colony, Shastri Nagar & 61 & 8 & 179 & 12 & 13.1 & 6.7 & 19.6 \\
\hline Jyoti Nagar, Shastri Nagar & 20 & 2 & 56 & 4 & 10 & 7.1 & 20 \\
\hline Beriya Colony I, II & 65 & 26 & 202 & 36 & 40 & 17.82 & 55.38 \\
\hline Rajeev Nagar, Kachchi Basti & 31 & 6 & 88 & 12 & 19.3 & 13.6 & 38.7 \\
\hline Bajarang Nagar & 40 & 8 & 228 & 12 & 20 & 5.2 & 30 \\
\hline Khati Pura, Shastri Nagar & 75 & 23 & 254 & 44 & 30.6 & 17.3 & 58.6 \\
\hline Swarn Kar Colony & 32 & 7 & 263 & 7 & 21.8 & 2.6 & 22.8 \\
\hline Verma Colony, Shastri Nagar & 33 & 5 & 236 & 12 & 36.3 & 5.0 & 15.1 \\
\hline Indra Puri Colony & 51 & 10 & 213 & 11 & 21.5 & 3.1 & 19.6 \\
\hline Khora Bisal, Jairam Pura & 109 & 28 & 377 & 44 & 25.6 & 11.6 & 40.3 \\
\hline Shri Ram Tila & 37 & 5 & 224 & 6 & 13.5 & 2.6 & 16.2 \\
\hline Mohan Nagar & 39 & 16 & 220 & 22 & 41 & 10 & 56.4 \\
\hline Shiv Nagar, Murli pura & 20 & 3 & 29 & 4 & 15 & 13.7 & 20 \\
\hline Purohit Bara, Pathan chowk & 15 & 9 & 18 & 9 & 60 & 50 & 60 \\
\hline Mazdoor Nagar, Rail. Colony I\&II & 166 & 36 & 249 & 67 & 21.68 & 26.90 & 40.36 \\
\hline Chand Pole & 33 & 7 & 224 & 10 & 21.2 & 4.1 & 30.3 \\
\hline
\end{tabular}




\begin{tabular}{|c|c|c|c|c|c|c|c|}
\hline Kamala Neharu Nagar & 23 & 17 & 139 & 23 & 53 & 16.5 & 71.8 \\
\hline Vyas Colony & 35 & 16 & 181 & 22 & 45.7 & 12.1 & 62.8 \\
\hline Hari Nagar & 33 & 4 & 163 & 5 & 12.1 & 3.1 & 13.1 \\
\hline Sanganer & 20 & 14 & 42 & 26 & 70 & 61.9 & 130 \\
\hline Raigar Basti & 30 & 11 & 232 & 26 & 36.6 & 11.2 & 86.1 \\
\hline Vidyadhar Nagar area, Kachchi Basti, & 289 & 92 & 1020 & 163 & 31.83 & 15.98 & 56.4 \\
\hline $\begin{array}{c}\text { IAS Coly, Gandhi Nagr, Govt. Bung Tonk } \\
\text { road }\end{array}$ & 34 & 17 & 188 & 35 & 50 & 18.61 & 102.94 \\
\hline & 2035 & 651 & 7104 & 1054 & 37.45 & 21.86 & 57.59 \\
\hline Commercial areas and Public places & & & & & & & \\
\hline Sindhi Camp, Bus stand & & & 21 & 4 & & 19.04 & \\
\hline Heera Bagh, (RFPIC Training Centre) & & & 30 & 10 & & 26.31 & \\
\hline Rajput Sabha Bhavan & & & 13 & 6 & & 46.15 & \\
\hline Rajput Hostel & & & 72 & 6 & & 8.33 & \\
\hline Sent Wilfred College, Mansarovar & & & 18 & 6 & & 33.3 & \\
\hline Railway station & & & 84 & 19 & & 22.6 & \\
\hline Railway Hospital & & & 25 & 3 & & 12 & \\
\hline Mosque & & & 7 & 4 & & 57.14 & \\
\hline Temple & & & 10 & 7 & & 70 & \\
\hline Gurdwara (Sikh temple) & & 461 & 113 & & 31.98 & \\
\hline
\end{tabular}

\section{Vector Control Measures to Contain Epidemics}

For control of VBDs and prevention depends on reducing mosquito population through source reduction and reducing contact between mosquito and people, enhanced surveillance at community level by the Integrated Disease Surveillance Programme (IDSP) for detection of primary case and Gullian Barre Syndrome. Maternal and child health division is advised to look for clustering of cases of microcephaly among new borne including and to watch on passengers returning from affected areas of ZIKVD and suffering from febrile illness. Rapid Response Teams (RRTs) have been advised to all levels for investigation of suspected outbreaks. In laboratory diagnosis, NCDC, Delhi and NIV, Pune are to support the outbreak investigation and for confirmation of laboratory diagnosis. The SHAs have to create increased awareness among clinicians including obstetricians, pediatricians and neurologists about ZIKVD and its possible link with adverse pregnancy outcome (fetal loss, microcephaly). Non-governmental organization should also be sensitized about ZIKVD.

Vector control is the only way to interrupt the transmission of VBDs such as Dengue, Chikungunya and Zika and can be achieved by include enhanced IVM, larval and adult surveys, for early detection of Aedes mosquitoes. ${ }^{5}$ So that, proper control measures could be initiated to eliminate mosquito breeding and adult mosquito population, environment management methods are used to control immature stage of Aedes mosquitoes. Essential efforts could be taken to reduce potential larval breeding habitats in houses and around houses by covering all water containers to prevent fresh egg laying by the vector. ${ }^{7}$ Additional efforts to emptying, drying water tanks, containers, coolers, bird baths, pets' water bowls, plant pots, drip trays at least once each week. Introducing larvivorous fishes (e.g. Gambusia/ Guppy) in ornamental water tanks/garden. Use the endotoxin producing bacteria, Bacillus thuringiensis as larvicide in stagnant water while no dangerous to humans, non-targeted organism, or environment when used according to directions. ${ }^{12}$ Temephos (organophate compound) is as a larvicide under public health programme. Synthetic Pyrethroids (SP) as an adulticide can be used for Indoor Residual Spray (IRS) in areas where imported cases of Dengue, Chikungunya, and Zika are detected..$^{13}$

Pyrethrum spray/malathion fogging can be applied for the control of adult Aedes mosquitoes. Personal protective/ 
prevention measures can be initiated by using insect repellent; wearing light-colored clothes preferably for the more coverage as much of the body as possible; closed doors and windows; sleeping under mosquito nets and should use insecticide-treated mosquito nets to provide more protection for mosquitoes biting. ${ }^{5}$ In areas where ZIKV is transmitting, the community must follow personal preventive measures. Legislative Measures as suitable laws and byelaws should be enacted and implemented for avoidance of situations which favor mosquito breeding at various levels. Health education for community mobilization and inter-sectoral convergence like community participation to eliminate the breeding sites of Aedes mosquitoes with the involvement of other sectors/ departments should be encouraged as per National guidelines for prevention of ZIKVD. ${ }^{10}$

\section{Result}

During the study 2035 houses were randomly checked to Aedes mosquito breeding, out of which mosquito breeding could be detected in 651 houses (in all kinds of water holding domestic containers in indoors and outdoors) in residential areas. In all the houses, 7104 domestic water containers were checked, out of which 1054 were positive for Aedes mosquito breeding (indoor or outdoor). The House Index ( $\mathrm{HI})$, Container Index $(\mathrm{Cl})$ and Breteau Index (BI) were $37.45,21.86$ and 57.59 respectively. Ten commercial areas and public places like Bus Stand, Railway Station, Railway Hospital, Fort, Mosque, Temple and Gurdwara (Sikh temple), Training Centre, Sabha Bhavan, Hostel and College were checked and all were found positive for Aedes breeding and over all $\mathrm{Cl}$ was 39,98 (Table 1). Ae. aegypti was the predominant species in various localities like residential, commercial and public places in Jaipur, while Ae. albopictus breeding was detected in the garden and parks. Larval stages of Ae. aegypti mosquito was found in all Zika affected municipal wards of Jaipur but vary from ward to ward, irrespective to Zika cases reported in these localities. Ae. albopictus breeding were also found in various water holding containers mostly in garden and parks in all the study areas.

The distribution pattern of immature stage of Aedes mosquitoes and Breeding Preference Ratio (BPR) in different types of breeding habitats (water containers) indoors or outdoors is depicted in (Table 2). The results of BPR showed the highest positivity of Aedes breeding in cemented tank in houses or nearby houses left in open spaces during the entomological investigations (2.11), followed by Mud pots for drinking of birds (1.39), domestic desert coolers (1.23), fountains (1.16), flower pots (0.84), Junk materials $(0.75)$ and discarded tyres (0.59) in the entire locality (Table 2). In addition, breeding of Aedes was also detected in earthen pots (0.26) and drums/ tubs/ tank (0.13).

The results of this study showed that Zika cases were declined with mosquito density and larval indices, when vector control measures and special efforts undertaken by the state health authority to interrupt Zika transmission and reduce mosquitoes breeding by using temephos for larval control of Aedes mosquitoes and synthetic pyrethroids like pyrethrum spray/ malathion fogging for the adults control, and also SP used for IRS activities and prevention measures initiated to protect mosquitoes biting.

Table 2.Breeding Preference Ratio (BPR) of Aedes in Zika affected areas in Jaipur city

\begin{tabular}{|c|c|c|c|c|c|}
\hline \multirow{2}{*}{ Breeding habitats of Aedes } & \multicolumn{3}{|c|}{ Number of containers } & $\begin{array}{c}\text { Breeding preference } \\
\text { ratio (BPR) }\end{array}$ \\
\cline { 2 - 6 } & Examined & X\% & $\begin{array}{c}\text { Positive for Aedes } \\
\text { breeding }\end{array}$ & Y\% & Y/X \\
\hline Domestic desert coolers & 2103 & 27.78 & 392 & 34.35 & 1.23 \\
\hline Flower pots & 322 & 4.25 & 41 & 3.59 & 0.84 \\
\hline Earthen pots & 564 & 7.45 & 32 & 2.01 & 0.26 \\
\hline Cement tanks & 1541 & 20.35 & 491 & 43.03 & 2.11 \\
\hline Discarded tyres & 213 & 2.81 & 19 & 1.66 & 0.35 \\
\hline Fountains & 23 & 0.30 & 4 & 2.97 & 1.16 \\
\hline Tubs/ drums/ OHTs & 1703 & 22.49 & 34 & 0.78 & 0.13 \\
\hline Mud pots for drinking of birds & 43 & 0.56 & 9 & 10.42 & 1.39 \\
\hline Junk materials & 1048 & 13.84 & 119 & & 0.75 \\
\hline Total Containers & 7570 & & 1141 & \\
\hline
\end{tabular}




\section{Discussion}

During the Zika outbreak investigations in Jaipur city showed the Ae. aegypti is well-established within the urban area due to high breeding, thus showing the possibilities for future outbreak of dengue, chikungunya and Zika in the areas at any time. Jaipur city has irregular piped water supply resulting in establishment of water storage practices in all kinds of big or small containers in indoors or outdoors in all the residential areas for household purposes. The practices of house holders (for the water storage for household purposes) were found as main reason for high Aedes mosquito breeding in Jaipur city. The larval indices were recorded above the critical level in all the entire localities (i.e. $>10$ ) and most of people in Jaipur city adopted water storage practices due to insufficient and unreliable water supply as noticed. Most of people in study area, the domestic water storage containers were left in houses or outside the houses without lid, because mostly people may not be aware of these factors persuading to mosquito breeding conditions. Similar observations were observed from this area by Katyal $R$ et al. and have suggested that IEC activities with source reduction are the 'must' activity for containing Aedes borne diseases. ${ }^{14}$ Another similar observation was recorded by the previous workers from the residential area of Calcutta city by Tandan $\mathrm{N}$ et al. ${ }^{15}$ and by Kalra NL in North, North-east and central India. ${ }^{16}$

During the Zika outbreak in Jaipur city, Aedes breeding was found in all the Zika affected wards but mosquito breeding was found to vary from ward to ward, irrespective of Zika cases, this supporting earlier research workers similar studies were conducted in different states in India as Uttarakhand, Jharkhand, Maharashtra and Delhi ${ }^{17-20}$ and similar finding were recorded also in Uttarakhand and Jharkhand Aedes disposition varied from area to area, and similar spatial pattern of Aedes mosquitoes was reported from Ajmer district of Rajasthan. ${ }^{16}$ However Ae. aegypti was recorded in domestic breeding habitats in houses or outside the houses left open space. Ae. albopictus breeding was detected outdoor of the house may be due to adaptation of Ae. albopictus in manmade habitats besides restriction of natural habitats and more attention be paid to clarify the involvement of Ae. albopictus in the transmission dynamics of Zika infection and could be studies on determination of possible role of $A e$. albopicus mosquitoes in maintenance of urban cycle regarding dengue, chikungunya and Zika as earlier reported by Joshi et al. ${ }^{21}$ Most of Aedes mosquito breeding was recorded in manmade breeding habitats in houses or outside the houses in cemented tanks, followed by Mud pots for drinking of birds, domestic desert coolers, fountains, flower pots, junk materials and discarded tyres.

During the survey, prevalence of Aedes mosquitoes was declined after the intervention measures for vector control were adopted by the state health department and IRS activity should be used to control vector population during the outbreak situation as suggested by Das MK et al. ${ }^{13}$ However, all the observations are suggesting that IEC with source reduction programme should be under taken before the transmission season to proper disposal of these mosquito breeding habitats with special attention to control mosquito breeding in Jaipur city for effective vector control of VBDs like Zika, dengue and chikungunya because there is no vaccine available for prevention of Zika infection.

\section{Conclusion}

It is concluded that the most of Zika affected areas in Jaipur city showing high larval indices were above the critical level in most of entire localities may be the probable reason for Zika outbreak. The entomological studies should be undertaken and the information could be utilized to forecast the possibility of future outbreak of Zika and necessary control measures should be taken before the possible outbreak in Jaipur city including rural area. This could be achieved by the enhanced IVM with special programme for water management practices, IEC activities and community participation to contain mosquito breeding sites or proper disposal of mosquito breeding to contain epidemics in future.

\section{Acknowledgement}

The authors are thankful to the Regional Director, Medical officers and their field staff of Regional Office for Health \& Family Welfare (ROHFW), Govt. of India, Jaipur and State Health Authorities, Jaipur for their active involvement and great assistance during the field study.

\section{Conflict of Interest: None \\ References}

1. World Health Organization. Available from: http://www. who.int/en/news-room/facts-heets/detail/zika-virus. Accessed 7 July, 2019.

2. World Health Organization. Zika virus infection. Available from: http://www.who.int/emergencies/ disease/zika/india-november2018/en/. Accessed 3 July, 2019.

3. World Health Organization. Zika-virus infection: India. Weekly Epidemiol Rec 2 Nov 2018. Available from: http://www.who.int/emergencies/disease/zika/en. Accessed 3 July, 2019.

4. National Vector Borne Disease Control Programme. Ministry of Health and Family Welfare. Available from: http://nvbdcp.gov.in/. Accessed 3 July, 2019.

5. World Health Organization. Prevention and control of dengue and dengue hemorrhagic fever comprehensive guidelines. WHO Regional Publications SEARO, 1999; 9.

6. Pant CP, Jatanasen S, Yasuno M. Prevalence of Ae. aegypti and Ae. albopictus and observations on the 
ecology of dengue haemorrhagic fever in several areas of Thailand. Southeast Asian Jour Trop Med Pub Healt 1973; 4: 113-121.

7. Guidelines for integrated vector management for control of Aedes mosquito. Available from: http:// www.mohfw.nic.in/. Accessed 3 July, 2019.

8. Official Site of Jaipur. Available from: http://jaipur. rajasthan.gov.in/content/raj/jaipur/en/about-jaipur/ geographical-and-physical-features.html.

9. Sheppard PM, Macdonald WW, Tonn RJ. A new method of measuring the relative prevalence of Aedes aegytpti. Bull WHO 1969; 40: 467.

10. Guidelines on Zika Virus Disease. Available from: http:// www.mohfw.nic.in/media/disease-alerts/nationalguidelines-zika-virus-disease/. Accessed 3 July, 2019.

11. Das BP and Kaul SM. Pictorial key to the common Indian species of Aedes (Stegomyia) mosquitoes. Jour Com Dis 1998; 30: 123-127.

12. Singh RK, S Haq, Kumar G et al. Insecticide susceptibility status of dengue vectors Aedes aegypti and Aedes albopictus in India: A review. WHO Deng bull 2013; 37: 177-191.

13. Das MK, Singh RK, Dhiman RC. Susceptibility of Aedes aegypti Linn to insecticides in Ranchi city, Jharkhand, India. WHO Deng bull 2011; 35: 194-198.

14. Katyal R, Mathur KK, Kaushal K et al. Risk factors involved in the transmission of Dengue/ DHF in some selected localities of Jaipur (Rajasthan). Jour Com Dis 2011; 43: 81-83.

15. Tandon N, Roy S. Breeding habitats and larval indices of Aedes aegypti and Aedes albopictus in the residential area of Calcutta city. Jour Com Dis 2000; 32(3): 180-184.

16. Kalra NL, Ghosh TK, Pattanayak S et al. Epidemiological and entomological study of an outbreak of dengue fever at Ajmer, Rajasthan in 1969. Jour Com Dis 1976; 8: 261-279.

17. Singh RK, Dhiman, RC, Dua VK et al. Entomological investigations during an outbreak of Dengue fever in Lal Kuan town, Nainital district of Uttarakhand, India. Jour Vec Bor Dis 2010; 47(3): 189-192.

18. Singh RK, Das MK, Dhiman RC et al. Preliminary investigation of Dengue vectors in Ranchi, India. Jour Vec Bor Dis 2008; 45(2): 171-173.

19. Singh RK, Mittal PK, Yadav NK et al. Susceptibility of Aedes aegypti Linn to insecticides in Ranchi city, Jharkhand, India. WHO Deng Bull 2011; 35: 131-140.

20. Singh RK, Mittal PK, Kumar G et al. Prevalence of Aedes mosquitoes in various localities of Delhi during dengue transmission season. Entomol App/ Sci Let 2014; 1(4): 16-21.

21. Joshi V, Singh M, Mourya DT. Studies on determination of possible role of Aedes albopictus mosquitoes in maintenance of urban cycle of dengue. Desert Medicine
Research Centre (Indian Council of Medical Research) Jodhpur. Annual Report 2003; 58-65. 